\title{
Distopia e $(m)$ paratradução: reescrevendo Margaret Atwood para o público brasileiro
}

\author{
Juliana Cristina Salvadori* \\ Daiane Alves Silva**
}

\begin{abstract}
Resumo
Este trabalho, fruto de pesquisa de iniciação científica (Bolsa CNPq), apresenta as traduções/reescritas de narrativas distópicas da escritora canadense Margaret Atwood, publicados no Brasil pela editora Rocco entre os anos de 2000 e 2019. Analisam-se os paratextos (capas, contracapas e orelhas) para compreender como esses elementos reescrevem a escritora e suas obras para o público brasileiro, criando um cânone doméstico de sua produção. Como fundamentação teórico-metodológica toma-se EvenZohar (1990) e outros, sobre teoria de polissistemas; Venuti (2019) sobre cânone doméstico; Lefevere (2007), sobre reescrita e tradução literária; Kathryn Batchelor (2020) e Câmara (2014) sobre paratexto e paratradução. Para o gênero distopia, fundamenta-se em Margaret Atwood (2005), entre outros. Das 6 narrativas distópicas de Atwood, 5 foram publicadas no Brasil pela editora Rocco, e apresentam reedições, em consonância com a maior popularização da escritora, a partir de 2017. As narrativas distópicas de Atwood são publicadas pelo selo principal, e não pelo selo jovem da editora, atestando que a escritora entra no sistema literário brasileiro como escritora de prestígio, e não pelas margens, lócus da literatura traduzida. Com suporte do programa AntConc, observa-se nos paratextos que a escritora e as obras são associadas inicialmente ao gênero de ficção científica e posteriormente à ficção especulativa ou distopia, e destaca-se a notoriedade da escritora, prêmios recebidos e circulação das obras. O cânone doméstico da autora se concentra nos seus romances, deixando em segundo plano suas outras produções ficcionais e crítico-teóricas, tomadas como base teórica em diálogo com sua reescrita no Brasil.

Palavras chave: Reescrita. Distopia. Cânone doméstico. Paratextos. Margaret Atwood.
\end{abstract}

\footnotetext{
* Universidade do Estado da Bahia (UNEB). Doutora em Literaturas de Língua Portuguesa pela PUC Minas. Professora Adjunta da Universidade do Estado da Bahia, Campus IV, Jacobina. ORCID (0000-0002-0565-5036).

* Universidade do Estado da Bahia (UNEB). Graduada em Letras Língua Inglesa e Literaturas pela Universidade do Estado da Bahia, Campus XXIII, Seabra. ORCID (0000-0003-2739-1833).
}

Cadernos CESPUC de Pesquisa. Série Ensaios. n.38, 10 Sem./2021, p. 114-133. e-ISSN: 2358-3231 (OJS). Recebido em: 23/07/2021. Aceito em: 07/og/2021. 


\title{
Dystopia and/in Paratranslation: Rewriting Margaret Atwood to Brazilian Readers
}

\author{
Juliana Cristina Salvadori \\ Daiane Alves Silva
}

\begin{abstract}
This study, funded by $\mathrm{CNPq}$, presents the translations/rewritings of Margaret Atwood's dystopias, published in Brazil from 2000 to 2019 by Editora Rocco.The paratexts (cover, back cover, flap) analyzed illuminate how these elements rewrite the author and her works to Brazilian readers, constructing a domestic canon of them. Theoretical frameworks is based on Even-Zohar (1990) regarding polysystem theory; Venuti (2019) regarding domestic canon; Lefevere (2007), regarding translation and rewriting; Kathryn Batchelor (2020) and Câmara (2014) on paratexts e paratranslation; Margaret Atwood (2005) on dystopia. Five out of six dystopian narratives by Atwood were translated and published in Brazil by editora Rocco, and reprints issued from 2017 on. Atwood's dystopian narratives are issued by the main editorial imprint, not by young adult literature imprint, pointing the place Atwood and her works hold, in the center of the literary system, even though translated literature tends to be placed in the margins. Freeware concordance program AntConc was used to analyze the paratexts. The findings show the works are labeled as science fiction works, at first, and to speculative fiction and dystopia, lately; the paratexts also stress the author: her fame, prizes and the worldwide reach of her works. Her domestic canon in Brazil consists mainly of novels, leaving her other fictional works and critical-theoretical ones in the background, particularly those which discusses her writing, used in this work as critical support to understand her rewriting in Brazil.
\end{abstract}

Keywords: Rewriting. Dystopia. Domestic Canon. Paratexts. Margaret Atwood. 


\section{Contextualização e demarcação teórico-metodológica}

Este trabalho de pesquisa apresenta a análise dos elementos paratextuais dos textos distópicos da escritora Margaret Atwood publicados pela editora Rocco, a fim de compreender sua reescrita e formação de cânone doméstico no sistema literário brasileiro.

Para construção da base teórica, tomamos a teoria de polissistemas, apresentada por Itamar Even-Zohar (1990) e discutida por Carolina Alfaro de Carvalho (2005) e John Milton (1998). Entendemos que o polissistema compreende a cultura, constituída por vários sistemas que se intercalam e se relacionam, dentro da qual também se estabelecem relações de poder entre os elementos integrantes, definidas por Even-Zohar (1990) como centro e periferia. No polissistema cultural se insere o literário, dinamizado pela participação de atores tanto internos quanto externos, são eles: o produtor, conceito que abrange os atores e criadores de textos literários; o consumidor, que não se limita apenas ao leitor e à atividade de ler ou ouvir textos, podendo ter um caráter direto, que consome o texto literário propriamente dito, ou indireto, que tem contato com fragmentos de textos, como resenhas e críticas; temos também a instituição, que são regras que definem modelos para a produção literária e a aceitação de produtores e agentes, compreendendo parte dos produtores, críticos, editores, instituições, o mercado, em que ocorre a venda e a compra de produtos literários, sendo um elemento que também se constitui um sistema e se relaciona com a instituição; o repertório, conjunto de regras e materiais que regem o sistema literário, seus elementos constituintes, suas atividades e produções; e, por fim, o produto, que não se limita ao texto literário, compreende também os diversos níveis de textos que se relacionam entre si.

No polissistema literário, também se integra o polissistema de tradução literária, o qual abrange elementos que se relacionam e agem de forma dinâmica interferindo nos processos de escrita, produção, tradução, recepção e circulação de textos. A literatura traduzida pode ocupar uma posição periférica ou central no sistema literário, a depender da manifestação dos repertórios consumidores ou inovadores de uma dada cultura. Parte 
do nosso trabalho objetiva compreender a posição e publicação dos textos literários mapeados no nosso sistema literário.

Para tanto, trabalhamos também com as concepções de reescrita, apresentadas por André Lefevere (2007) em Tradução, reescrita e manipulação da fama literária”. Para Lefevere (2007), reescritas compreendem não só as traduções propriamente ditas, mas também as edições, antologizações, críticas, resenhas, resumos, artigos críticos, ou outras formas, como adaptações para o cinema ou televisão. Tais reescritas, segundo o autor, "manipulam e são eficientes", podendo ter um impacto significativo na cultura de chegada; além disso, sua produção é influenciada por fatores ideológicos e culturais da cultura em que integra.

Atrelado a essa relação da reescrita com a cultura de circulação, também nos fundamentamos nas ideias de Venuti (2019) sobre cânone doméstico de um autor ou gênero, o autor destaca destaca a tradução como um fator importante na "construção de representações de culturas estrangeiras", uma vez que o estabelecimento de cânones domésticos ocorre em decorrência da escolha de textos estrangeiros a serem traduzidos e das estratégias de tradução empregadas nesses textos. Para Venuti, as reescritas dos textos se amoldam a "estilos e temas que prevalecem naquele período nas literaturas domésticas” (VENUTI, 2019, p. 138). Além disso, o autor explica a recorrente tendência à escolha de best-sellers, obras que obtém sucesso de vendas no país de origem e ganham a atenção das editoras, demonstrando uma preocupação do mercado editorial com o fator econômico.

Sendo a reescrita um fenômeno que compreende não só as traduções propriamente ditas, mas também elementos paratextuais, faz-se relevante a compreensão da concepção de paratextos e paratradução, foco da análise deste trabalho. Essa discussão é abordada por Kathryn Batchelor (2020) e Elisa Oliveira Câmara (2014), que se baseiam nas concepções de Genette (2009). Para Genette, os paratextos são os elementos que acompanham o texto e compreendem elementos como: capas, contracapas, orelhas, prefácio, posfácio e introdução; compreendem também aqueles externos à obra, que se relacionam de certa forma com o texto, os quais são chamados epitextos, como as resenhas, críticas etc. Segundo Câmara (2014), os paratextos se fazem presentes em toda forma de comunicação textual, pois, para Genette, não existe texto sem paratexto, e esses elementos são a porta 
de entrada do leitor para o texto literário. Além disso, Câmara destaca que o tradutor raramente participa do processo de elaboração paratextual.

A partir da análise dos elementos paratextuais, selecionamos as publicações das traduções dos textos distópicos da escritora canadense Margaret Atwood, pela editora Rocco, que recebem um destaque significativo no catálogo da editora, sendo publicados pelo selo principal. São cinco textos publicados pela editora Rocco, a saber: $O$ conto da aia (2006, 2017), Oryx e Crake (2004, 2018), O ano do dilúvio (2011, 2018), MaddAddão (2019) e Os Testamentos (2019). Assim, com suporte no programa AntConc, realizamos a análise paratextual como os seguintes elementos: capas, contracapas e orelhas. ${ }^{1}$ Com isso, percebemos uma padronização no design gráfico das reedições feitas a partir de 2017, além do destaque, nas orelhas dos livros, para suas obras de sucesso e prêmios recebidos, além da oscilação na categorização do gênero literário.

Para entender essa oscilação, abordamos, na segunda seção deste texto, "Distopia e ficção especulativa: os não lugares dos subgêneros", a conceituação e características desses subgêneros ficção especulativa e distopia, tomando como base a produção ensaística da escritora Margaret Atwood, bem como autores como Tom Moylan e outros, destacando as fronteiras com subgêneros correlatos, como a ficção científica. A partir das considerações e discussão teórica delineadas, seguimos para a terceira seção: "Distopias de Margaret Atwood para o público brasileiro", com a análise dos elementos paratextuais (capas, contracapas e orelhas). Na quarta e última seção, "Considerações e especulações", tecemos considerações sobre a análise da reescrita das narrativas distópicas da escritora e seu lugar no polissistema literário brasileiro.

\section{Distopia e ficção especulativa: os não lugares dos subgêneros}

Nos séculos XX e XXI, as narrativas distópicas reemergem, ganhando notoriedade e público, e ampliando seu alcance, principalmente

\footnotetext{
1 Os textos das orelhas dos livros analisados não possuem indicação de autoria específica. Os textos que compõem as contracapas trazem citações em forma de comentários preferencialmente de autor(as) e críticos conhecidos, publicados em veículos de comunicação consagrados. Cada um dos romances, em suas contracapas, abarcam as respectivas referências: O conto da aia (2 ed. 2017): Angela Carter; The Guardian; Washington Post; Time Out. Oryx e Crake (2 ed. 2018): The New Yorker; The Baltimore Sun; The Seattle Times; Times Out New. O ano do dilúvio, (2 ed. 2018): Elle; The Los Angeles Times; The Washington Post; Kansas City Star. MaddAddão (2019): The Independent; The New York Times; Alice Munro; Germaine Greer.
}

Distopia e(m) paratradução: reescrevendo Margaret Atwood para o público 118 brasileiro 
entre o público jovem, com novos modelos, discussões, vertentes. As adaptações cinematográficas e televisivas popularizaram o gênero e dão corpo às inquietações advindas de contexto rupturas, disputas e guerras que marcam o mundo político e social.

Mas o conceito de distopia, que vai além da literatura (se estende também a campos de estudo sociológicos e culturais), é amplo e estritamente ligado ao de "utopia", o qual compõe um campo de estudos interdisciplinar intitulado Utopian Studies. Na literatura, a circunscrição do gênero abarca textos de diferentes vertentes e questões, os quais, influenciados pelo contexto histórico e social em que foram produzidos, concebem novos subgêneros, apontam estudiosos como Lyman Tower Sargent e Tom Moylan, dentre eles a "antiutopia" e a "distopia". É importante ressaltar que utopia e distopia são conceitos correlatos, como salienta a escritora Margaret Atwood (2011) ao criar o termo ustopia: "[...] é uma palavra que eu criei ao combinar utopia e distopia - a sociedade perfeita imaginada e seu oposto - porque, em minha visão, cada uma contém uma versão latente da outra" (ATWOOD, 2011b, p. 66, apud NETO, 2018, p. 34).

Margaret Atwood, em seu ensaio Writing Utopia, destaca que "as utopias costumam ser satíricas, sendo a sátira direcionada para qualquer sociedade em que o escritor esteja vivendo atualmente - ou seja, os arranjos superiores dos utopistas refletem mal em nós" (ATWOOD, 2005, p. 94, tradução nossa). ${ }^{2}$ A utopia assume um tom crítico voltado à realidade em que autor e leitor vivem, como um reflexo contrário, pois ao ser criada e descrita uma sociedade ideal e melhorada, o autor apresenta como este mundo "deveria ser". Aprofundando a correlação entre utopia e distopia, Atwood afirma ainda, que

A utopia é um exemplo extremo do impulso de ordenação; é a palavra deveria que corre desenfreada. A distopia, sua imagem espelhada como pesadelo, é o desejo de esmagar dissidências, levado a extremos desumanos e lunáticos. [...] Como regra, a utopia só é segura quando permanece fiel ao seu nome e permanece em lugar nenhum (ATWOOD, 2005, p. 95, ênfase da autora, tradução nossa). ${ }^{3}$

\footnotetext{
2 No original: "Utopias are often satirical, the satire being directed at whatever society the writer is currently living in - that is, the superior arrangements of the Utopians reflect badly on us".

3 No original: "Utopia is an extreme example of the impulse to order; it's the word should run rampant. Dystopia, its nightmare mirror image, is the desire to squash dissent taken to inhuman and lunatic lengths. [...] As a rule, Utopia is only safe when it remains true to its name and stays nowhere".
} 
Atwood, na sua definição, destaca que a distinção entre utopia e distopia está na possibilidade e intensidade em que o desejo de ordenação é posto em ação: o "deveria ser" da utopia de uns, sempre pode se tornar, no espelho, o pesadelo de outros, quando a ficção (sonho ou pesadelo) toca o mundo real e lhe ordena a partir de como "deveria ser".

Segundo Moylan (2000), no prefácio de seu livro Scraps of the Untainted Sky: Science Fiction, Utopia, Dystopia, uma característica marcante da distopia, que ele refere como "a verdade principal", é o fato desses textos realizarem uma reflexão sobre as causas do mal social e ecológico como algo sistematizado, estruturado. Assim, o texto distópico cria “[...] mundos alternativos nos quais o espaço-tempo histórico do autor pode ser reapresentado de uma maneira que privilegie a articulação de suas dimensões econômica, política e cultural", de modo a recusar "uma perspectiva funcionalista ou reformista"4 (MOYLAN, 2000, p. 12, tradução nossa). É importante destacar a menção ao "espaço-tempo histórico do autor", uma vez que esse texto considera, e reflete, a "realidade" de determinado tempo e lugar. Além disso, Moylan (2000) explica que, no texto distópico, não há o isolamento de um único elemento como o problema raiz ou como o único a ser corrigido, no que se refere a políticas, práticas, personagens, etc. Assim, os escritores ou leitores podem refletir, por identificação ou contra-identificação, indo além das realidades por eles vivenciadas (MOYLAN, 2000, p. 12).

Considerando que o texto distópico apresenta um lugar social fictício que aparenta ser pior do que o "real", Moylan (2000) também esclarece outra característica desse texto, que envolve o personagem em relação ao sistema social existente na trama. Enquanto nas utopias clássicas o personagem é um narrador testemunha que descreve em detalhes aquela sociedade melhorada, no texto distópico "o enredo se desenvolve em torno desse protagonista alienado, quando ele ou ela começa a reconhecer a situação pelo que realmente é e, assim, a rastrear a relação entre a experiência individual e a operação de todo o sistema"5 (MOYLAN, 2000, p. 13, tradução nossa). No entanto, destaca o autor, a narrativa pode ficar encalhada nessa problemática, quando o sistema opressor vence o indivíduo, ou se desenha a possibilidade de surgir esperança, o chamado "horizonte utópico", e uma

\footnotetext{
4 No original: "Its very textual machinery invites the creation of alternative worlds in which the historical spacetime of the author can be re-presented in a way that foregrounds the articulation of its economic, political, and cultural dimensions. Formally and politically, therefore, the dystopian text refuse a functionalist or reformist perspective".

5 No original: "The story line then develops around that alienated protagonist as she or he begins to recognize the situation for what it really is and thus to trace the relationship between individual experience and the operation of the entire system."
}

Distopia e $(\mathrm{m})$ paratradução: reescrevendo Margaret Atwood para o público 120 brasileiro 
certa resistência coletiva em oposição ao sistema (MOYLAN, 2000, p. 13), o que diferencia o texto distópico do antiutópico, conceitos muitas vezes tidos como sinônimos.

Contudo, destaca Margaret Atwood (2005), como ponto focal a se considerar na relação entre o mundo ficcional e o real, em contraste com a característica da sátira do texto utópico: "as distopias costumam parecer mais com avisos terríveis do que sátiras, como sombras escuras projetadas pelo presente no futuro. Elas são o que vai acontecer conosco se não nos esforçarmos para reverter certas problemáticas"' (ATWOOD, 2005, p. 94, tradução nossa). Ou seja, na narrativa distópica são apresentados mundos e sociedades com problemáticas que refletem problemas reais, especulados/espelhados, extrapolados, fomentando uma reflexão crítica e questionamentos sobre possibilidades negativas do presente. Logo, para a escritora, as distopias, podemos dizer, cumprem papel dos contos de fadas e fábulas na contemporaneidade, entendidas como cautionary tales, contos de advertência. Contudo, seriam esses problemas apresentados realmente extrapolados em relação à realidade, situados em um futuro negativo ou já acontecem ou aconteceram, de fato, em algum lugar da nossa história? Margaret Atwood também disserta quanto a isso, se referindo ao romance O conto da aia. Segundo ela,

[...] em The Handmaid's Tale, nada acontece que a raça humana ainda não tenha feito em algum momento no passado, ou que não esteja fazendo agora, talvez em outros países, ou para a qual ainda não desenvolveu a tecnologia. Já fizemos, ou estamos fazendo, ou podemos começar a fazer amanhã. Nada inconcebível acontece, e os papéis projetados nos quais minha futura sociedade se baseia já estão em movimento (ATWOOD, 2005, p. 92, tradução nossa). ${ }^{7}$

Essa associação com a realidade marca o projeto literário da autora relacionado, como a mesma frisa em entrevistas, ao gênero de ficção especulativa. Especulativa e espelho, afinal, indicam a relação de ficção ancorada no real, uma vez que ambos os termos compartilham, etimologicamente da mesma raiz, "specio", que significa ver, olhar: é com os olhos na realidade, não apenas na contemporaneidade, que Atwood

6 No original: "Dystopias are often more like dire warnings than satires, dark shadows cast by the present into the future. They are what will happen to us if we don't pull up our socks".

7 No original: "[...] in The Handmaid's Tale, nothing happens that the human race has not already done at some time in the past, or that it is not doing now, perhaps in other countries, or for which it has not yet developed the technology. We've done it, or we're doing it, or we could start doing it tomorrow. Nothing inconceivable takes place and the projected trends on which my future society is based are already in motion". 
produz sua ficção, ampliando os limites do que o romance como gênero compreende como realismo e que marca sua emergência como gênero literário em ascensão do século XIX e XX. A ficção especulativa na perspectiva de Atwood, portanto, para além do compromisso do romance realista de produzir para seu leitor uma experiência de vida contemporânea que torne o mundo ao seu redor inteligível, trabalha na perspectiva de tornar inteligível as várias experiências em contextos mais ou menos possíveis quando tomadas as nossas condições reais de existência.

A classificação das narrativas distópicas de Margaret Atwood como "ficção científica" é apontada pela autora como falha. Em Writing Utopia, ela considera o romance "[...] $O$ conto da aia não como ficção científica, mas como ficção especulativa; e, mais particularmente, como aquela forma negativa de ficção utópica que passou a ser conhecida como Distopia"8 (ATWOOD, 2005, p. 93, tradução nossa). Além disso, e se referindo ao primeiro livro da trilogia MaddAddam, a autora afirma que “assim como $O$ conto da aia, Oryx e Crake é uma ficção especulativa, não uma ficção científica propriamente dita" (ATWOOD, 2005, p. 285, apud P. L. THOMAS, 2013, p. 2, tradução nossa).

No que se refere à distinção entre esses gêneros, ficção científica e ficção especulativa, Margaret Atwood destaca:

Como em $O$ conto da aia, [Oryx e Crake] não inventa nada que ainda não inventamos ou começamos a inventar. Todo romance começa com "e se?" e então expõe seus axiomas. O “e se?" de Oryx e Crake é simplesmente: E se continuarmos no caminho em que já estamos? Quão escorregadio é o declive? Quais são nossas graças salvadoras? Quem tem vontade de nos parar? (ATWOOD, 2005, p. 285-286, ênfase no original, tradução nossa) $)^{10}$

De acordo com o exposto pela escritora, entende-se que a ficção especulativa se preocupa em especular sobre as possibilidades inscritas na realidade a partir do "e se?"; ou seja, a partir dessa especulação nas

\footnotetext{
8 No original: "So I think of The Handmaid's Tale not as science fiction but as speculative fiction; and, more particularly, as that negative form of Utopian fiction that has come to be known as the Dystopia".

9 No original: "Like The Handmaid's Tale, Oryx and Crake is a speculative fiction, not a science fiction proper".

10 No original: "As with The Handmaid's Tale, [Oryx and Crake] invents nothing we haven't already invented or started to invent. Every novel begins with a what if and then sets forth its axioms. The what if of Oryx and Crake is simply, What if we continue down the road were already on? How slippery is the slope? What are our saving graces? Who's got the will to stop us?".
}

Distopia e $(\mathrm{m})$ paratradução: reescrevendo Margaret Atwood para o público 122 brasileiro 
suas distopias, a narrativa relê o presente a partir de passados e futuros em convergência.

Sławomir Kuźnicki (2017), com base nas narrativas de Margaret Atwood, debate as convergências e divergências entre ficção especulativa, a distopia e utopia e a ficção científica. Segundo Kuźnicki, o encontro entre tais gêneros “[...] demonstra que eles estão tão inseparavelmente ligados um ao outro que é impossível determinar linhas divisórias definidas" (KUŹNICKI, 2017, p. 17); e cita Atwood (2011) afirmando que "quando se trata de gêneros, as fronteiras estão cada vez mais indefesas, e as coisas deslizam de um lado a outro despreocupadamente" (ATWOOD apud KUŹNICKI, 2017, p. 17, tradução nossa). ${ }^{11}$ Desse modo, o encontro desses gêneros em uma narrativa impacta nas classificações das obras e mostra quão tênues são as demarcações e fronteiras, como a análise dos paratextos para as traduções brasileiras atesta.

Conquanto seja um debate que precisa ser mais aprofundado, apresentamos na seção a seguir a análise de como, a partir das considerações sobre sua escrita e romances, e do arcabouço teórico-crítico esboçado, as narrativas distópicas da escritora são reescritas para o público brasileiro por meio dos paratextos, abrindo a porta de entrada para um horizonte de expectativas sobre o projeto literário da autora e suas obras no Brasil, isto é, seu cânone doméstico, compreendendo que o processo de reescrita é perpassado por escolhas editoriais, impactadas por questões econômicas e culturais, para além do domínio dos tradutores, que trabalham no texto.

\section{Distopias de Margaret Atwood para o público brasileiro}

Kathryn Batchelor (2020) discute paratextos e paratradução a partir dos conceitos de Gerard Genette (2009). Batchelor (2020) explica que, de acordo com Genette, os elementos paratextuais incluem "[...] encadernação e composição, capas, títulos, dedicatórias, prefácios e notas (elementos que são anexados ao texto e que Genette chama de peritexto), bem como elementos externos ao texto (epitextos), como comunicados de imprensa e

\footnotetext{
11 No original: "[...] it demonstrates that they are so inseparably linked to each other that it is impossible to determine definite dividing lines. As Atwood states: 'When it comes to genres, the borders are increasingly undefended, the things slip back and forth across them with insouciance".
} 
entrevistas com o autor" (BATCHELOR, 2020, p. 401, tradução nossa). ${ }^{12}$ Batchelor (2020), embasada em Genette, propõe que o estudo de paratextos focalize a sua função, uma vez que os paratextos, porta de entrada para o texto, convidam o leitor ao texto, ao comentar e influenciar a recepção do texto (BATCHELOR, 2020, p. 401), seduzindo o leitor e alimentando suas expectativas. Segundo a autora, Genette destaca a importância de se analisar os elementos que acompanham e introduzem o texto, pois os paratextos já anunciam e conformam expectativas de leitura a partir da categorização dos textos mediante certo repertório literário evocado pelo rótulo romance, ficção científica, etc.

Este argumento vai ao encontro das concepções de Lefevere (2007) e Even-Zohar (1990), em relação ao estudo das escritas, reescritas e das traduções, que não devem ser analisadas de forma isolada, mas abrangendo outros elementos e atores em um polissistema cultural do qual tanto a literatura quanto a literatura traduzida fazem parte. Para Even-Zohar (1990), a literatura traduzida é um dos elementos que fazem parte do sistema literário, o qual, por sua vez, compõe o polissistema da cultura. $\mathrm{O}$ autor salienta ainda que o sistema literário não se limita apenas ao texto literário, mas propõe que consideremos os diversos níveis de textos, e sua circulação, como resenhas, críticas, citações, parábolas curtas, etc. (EVENZOHAR, 1990, p. 41).

A exploração dos paratextos das traduções brasileiras das distopias da escritora canadense Margaret Atwood, e o modo como estas introduzem e apresentam a autora e seu projeto literário para o público brasileiro, conformando um cânone doméstico de sua obra, é o objeto desta investigação. Para leitura e transcrição dos paratextos, contamos com o suporte do software AntConc, um programa de análise de corpus. ${ }^{13}$

A escritora canadense publicou seis narrativas distópicas, cinco delas traduzidas no Brasil pela editora Rocco: 1. The Handmaid's Tale (1985), traduzida como $O$ conto da aia (1 ${ }^{\mathrm{a}}$ edição: 2006; $2^{\mathrm{a}}$ edição: 2017), por Ana Deiró; 2. Oryx and Crake (2003), traduzida como Oryx e Crake (1 ${ }^{\mathrm{a}}$ edição: 2004; $2^{\mathrm{a}}$ edição: 2018), por Léa Viveiros de Castro; 3. The Year of the Flood (2009), traduzida como $O$ ano do dilúvio (1 ${ }^{\mathrm{a}}$ edição: 2011; $2^{\mathrm{a}}$

\footnotetext{
12 No original: "[...] binding and typesetting, cover pages, titles, dedications, prefaces and notes (elements which are appended to the text and which Genette calls the peritext), as well as elements external to the text (epitexts) such as press releases and interviews with the author"

13 Para utilizar a ferramenta, os arquivos devem estar no formato de texto sem formatação, "txt", e UTF. AntConc é um software livre e mais informações, bem como seu download, estão disponíveis no site de seu criador: https://www.laurenceanthony.net/software/antconc/
}

Distopia e(m) paratradução: reescrevendo Margaret Atwood para o público 124 brasileiro 
edição: 2018), por Márcia Frazão; 4. MaddAddam (2013), traduzida como MaddAddão ( $1^{\mathrm{a}}$ edição: 2019), também por Márcia Frazão; 5. The Heart Goes Last (2015), ainda não possui tradução publicada no Brasil; 6. The Testaments (2019), traduzida como Os Testamentos ( $1^{1}$ edição: 2019), por Simone Campos.

Podemos observar que as reedições ocorreram a partir de 2017, sendo a primeira do romance $O$ conto da aia, texto que se tornou best-seller mundial, obtendo sucesso e ganhando adaptações para o cinema, teatro, ópera e para uma bem sucedida série de TV. A aclamada série, adaptação homônima do romance, estreou em 26 de abril de 2017, e a segunda edição do livro foi lançada no Brasil, pela Rocco, em 7 de junho de 2017, ou seja, pouco tempo depois da estreia da adaptação televisiva. No ano seguinte, Oryx e Crake e $O$ ano do dilúvio também tiveram novas edições publicadas. A estas publicações seguiram-se a primeira edição de MaddAddão, em 2019, e a rápida tradução e publicação de Os Testamentos, obra que sucede o romance $O$ conto da aia, também em 2019.

A partir desses dados, notamos que o investimento nas reedições e publicações pela editora ocorreu em consonância com o sucesso da série, isto é, em um momento de maior divulgação e popularização da escritora e sua obra, processo que ocorreu tanto no país de origem quanto no Brasil. Esse fenômeno das adaptações é discutido por Lefevere como reescrita e pode ser compreendido, na perspectiva de Genette, como um paratexto, uma porta de entrada para as obras de ficção da escritora, que abrange seu debate sobre ficção especulativa/ustopia, categorizada para o público brasileiro, nos paratextos, como distopia, subgênero que tem atraído os leitores à medida em que especula sobre as possibilidades, refletindo e levantando questionamentos sobre problemáticas emergentes na realidade.

Com exceção da contracapa de Os testamentos (2019), o nome da escritora e título do livro, da mesma forma e com o mesmo tamanho e fonte de letra que na capa, as dos demais livros contém frases de efeito, ou pequenas descrições da narrativa, ou, com exceção da primeira edição de Oryx e Crake (2004), possuem relatos ou citações de renomados jornais, revistas ou escritores que elogiam o livro e/ou a escritora. Desse modo, essa etapa dessa análise se foca nas contracapas e orelhas dos livros: $O$ conto da aia (2017), Oryx e Crake (2004 e 2018), O ano do dilúvio (2018) e MaddAddão (2019), e nas orelhas do livro Os testamentos. 
Essa classificação de gênero literário dos textos de Atwood é um dos pontos a se considerar. Para tanto, selecionamos o termo "ficção" na coluna de Lemma do software, e encontramos treze ocorrências. Após essa identificação, analisamos na seção Concordance o contexto em que o termo é usado. Percebemos que "ficção científica" aparece quatro vezes: na primeira edição de Oryx e Crake, na contracapa, em destaque, letras maiúsculas, na cor dourada e centralizada, em meio a uma frase de efeito, cujo texto está justificado e de cor preta. O texto em que aparece o destaque é: "Visão do futuro enraizada no presente, Oryx e Crake marca o retorno de Margaret Atwood à ficção científica". A segunda menção a esse gênero ocorre na segunda edição de $O$ conto da aia, em uma citação da escritora Angela Carter, que comenta " $O$ conto da aia é ao mesmo tempo um exercício insuperável em ficção científica e uma história moral de significado profundo"; a terceira menção ocorre na orelha da contracapa do mesmo livro, destacando que Atwood "transita em igual talento pelo romance, o conto, a poesia e o ensaio, se destacando também por suas sólidas incursões no terreno da ficção científica, em obras como Oryx e Crake e $O$ ano do dilúvio". A quarta ocorrência está na segunda edição de Oryx e Crake, na orelha da contracapa, que apresenta características e elementos da narrativa, e inicia comentando "O primeiro de uma trilogia que inclui $O$ ano do dilúvio e se encerra com MaddAddão, Oryx e Crake consolida o retorno de Margaret Atwood ao gênero da ficção científica [...]”. Nessa orelha, como também na da capa, também é mencionado o gênero "ficção especulativa", se referindo ao livro $O$ conto da aia. Ou seja, enquanto essa edição considera os dois primeiros livros da trilogia MaddAddão como ficção científica, $O$ conto da aia já é classificado como ficção especulativa.

$\mathrm{Na}$ edição de Os testamentos (2019) a palavra ficção aparece na orelha da contracapa, mas como referência aos gêneros literários que a escritora produz, "ficção, poesia, ensaios e graphic novels", salientando quão profícua é a produção da escritora. Já nas demais edições estudadas, a classificação feita é de ficção especulativa, sendo que há seis ocorrências de ficção especulativa.

Souza (2014) e Thomas (2013) discorrem sobre a tensão que a classificação por gêneros literários gera, tanto pelas divergências entre definições e delimitações entre gêneros, por parte dos diversos atores que participam do sistema literário, quanto pela dificuldade em estabelecer as

Distopia e(m) paratradução: reescrevendo Margaret Atwood para o público 126 brasileiro 
convenções dos gêneros que transitam por textos multimodais (impressos, digitais, audiovisuais).

O termo "distópico", por sua vez, apresenta três ocorrências nas edições de $O$ ano do dilúvio (2018), Oryx e Crake (2018) e MaddAddão (2019), se referindo ao cenário em que as narrativas estão situadas. O termo “distópica" ocorre em $O$ conto da aia (2017), na orelha da contracapa, indicando que o romance retoma "a tradição dos clássicos da literatura distópica, como 1984 e Admirável mundo novo sob uma perspectiva original e feminina [...]". Em Os testamentos, o texto da orelha da capa se refere ao romance $O$ conto da aia como "obra prima distópica de Margaret Atwood". Logo, o termo "distopia" emerge nos paratextos como adjetivo, caracterizando a temática e ambiência das narrativas.

Dos termos buscados, o sobrenome da escritora é o que apresenta mais ocorrências, contabilizando vinte e oito. Em síntese, nas citações presentes nas contracapas, o sobrenome emerge ressaltando o destaque da autora e qualidade da sua escrita e da narrativa em específico. Nas orelhas das contracapas das três reedições mencionadas e da edição de MaddAddão, os textos referentes à escritora são semelhantes, descrevem-na como uma das maiores escritoras de língua inglesa, com destaque a alguns prêmios importantes que recebeu, como o Giller Prize, o Man Booker Prize e o Príncipe das Astúrias; destacam também as muitas publicações de suas obras pelo mundo, enfatizando sua tradução como índice do seu sucesso e da qualidade da sua escrita; destacam, ainda, os diferentes gêneros literários que produz, sinalizando sua vasta produção literária; evidenciam o sucesso das adaptações de suas narrativas; nomeiam os títulos importantes recebidos pela escritora (nas edições publicadas 2018 e 2019); e, ainda, listam outras obras da autora publicadas pela editora.

As orelhas das contracapas dos livros destacam os importantes prêmios recebidos pela escritora, bem como os diferentes gêneros que escreve, com menção à quantidade de obras, e quantidade de países para onde seus textos já foram traduzidos e publicados. Em quase todas as orelhas das contracapas, Atwood, é referenciada como "uma das maiores escritoras de língua inglesa". As edições mais recentes, Oryx e Crake (2018), $O$ ano do dilúvio (2018), MaddAddão (2019) e Os testamentos (2019), também citam títulos importantes que lhe foram atribuídos. Considerando também que a Rocco publicou vinte e quatro livros da escritora, de acordo 
com informações contidas no site oficial da editora, Margaret Atwood é reescrita de modo a ressaltar sua notoriedade, sua vasta produção literária, mostrando a relevância de sua escrita e temáticas abordadas, sendo que a categorização de suas obras oscila entre distopia e ficção científica, embora nas reedicções, a ficção especulativa, categoria defendida pela escritora como a adequada para o seu projeto literário, emerja.

Essas ocorrências apontam o status canônico com o qual a escritora chega no sistema literário brasileiro, mesmo como literatura traduzida, em particular pelo destaque que o nome da autora recebe nos paratextos, visto que uma das funções dos paratextos é seduzir os leitores bem como criar expectativas para a entrada no texto literário traduzido. A oscilação, também identificada na classificação dos trabalhos de Atwood, aponta como as edições, a partir dos anos 2010, passam a incorporar o debate que a própria escritora traça sobre sua escrita, ao fazerem menção à ficção especulativa nos paratextos, outro índice de que ela se torna autora e autoridade sobre sua obra frente ao público brasileiro, embora seus textos ensaísticos ainda não tenham recebido traduções para o público brasileiro, o que pode significar que o cânone brasileiro de Atwood destaca sua produção como ficcionista/ romancista, e não sua produção ensaística, tendência já observada na tradução das obras de outras escritoras estudadas pelo grupo de pesquisa Desleituras, como é o caso de Ursula K. Le Guin.

Os dados levantados apontam que sua ficção distópica recebe destaque significativo a partir de 2017, em que foram publicadas reedições em âmbito brasileiro, bem como novos textos e paratextos da autora, em âmbito mundial. As segundas edições dos romances $O$ conto da aia (2017), Oryx e Crake (2018), O ano do dilúvio (2018) e a primeira edição de MaddAddão (2019) apresentam um padrão de design gráfico nas capas, feito pelo ilustrador brasileiro Laurindo Feliciano, que se desdobra em mais três obras da escritora publicadas pela Rocco. Também verificamos que Os testamentos, sequência de $O$ conto da aia, lançado mundialmente em 10 de setembro de 2019, foi rapidamente traduzido e publicado pela editora Rocco no Brasil, em 9 de novembro de 2019, em consonância com o sucesso da série e do romance que o precede, e que foi bem aceito pelo público leitor, e, consequentemente bem vendido (como apontado em sucessivas listas de vendas em veículos da imprensa nacional). 
Notamos que a edição brasileira adotou o mesmo padrão gráfico da edição original, o que pode indicar que os textos de Atwood, pela fama da autora, podem ocupar uma posição central desse texto no sistema literário brasileiro mesmo que seja literatura traduzida - literatura traduzida tende a ocupar um lugar periférico em dado sistema literário, a não ser quando o sistema literário é considerado ainda em formação ou de pouco prestígio. Isto porque, de acordo com a concepção explicada por Even-Zohar (1990), não há a utilização de modelos do repertório doméstico, principalmente no que tange aos paratextos e à configuração das capas, mas sim à aproximação com o texto e repertório original, estrangeiro, aproximando as literaturas.

Em relação à análise dos paratextos (contracapas e orelhas dos textos), percebemos que a divergência em relação ao gênero narrativo é refletida em algumas edições: isso ocorre nas edições de Oryx e Crake (2004, 2019) e na segunda edição de $O$ conto da aia (2017), em que a autora e os textos são associados ao gênero de ficção científica: contabilizando um total de quatro menções, de acordo com os resultados obtidos pelo AntConc.

Nos paratextos das edições seguintes, contudo, as obras são classificadas como ficção especulativa, e/ou citando a característica distópica da narrativa, o que nos aponta que a maior circulação da autora em território brasileiro, por meio de traduções e paratextos, inclusive com produção crítico-teórica em processo inicial de tradução, qualifica o debate. Este achado também fortalece a interpretação de que Atwood entra no (poli)sistema literário brasileiro, principalmente a partir dos anos 2015, via literatura traduzida, não pelas margens, mas pelo centro, endossada pelas premiações e reconhecimento, o que, logo, autoriza os paratextos a produzir menos domesticações e menos aproximação com subgêneros mais populares (como ficção científica) e abrir espaço para o debate sobre ficção especulativa, ainda pouco explorado no Brasil, a não ser quando em diálogo com literatura estrangeira, particularmente a de língua inglesa.

\section{Considerações especulativas}

Margaret Atwood é uma escritora com produção prolífica que transita entre os mais diversos gêneros literários. Pereira e Salvadori (2020) 
destacam sua circulação para o público brasileiro via tradução: conquanto suas publicações iniciais datam do final da década 1960, ela se consolida como escritora reconhecida de ficção a partir da década de 1980, chegando ao Brasil a partir da década de 1990, mas mais fortemente nos anos 2000, principalmente a partir da década de 2010, pela editora Rocco. Os autores salientam ainda que entre as produções de Atwood encontramos: dezesseis (16) romances, dos quais quinze (15) estão traduzidos para o público brasileiro, e catorze (14) desses romances foram republicados duas vezes (na década de 90 ou na primeira década dos anos 2000 e republicados a partir de 2017), e os mais recentes ( The Penelopiad, Hag-Seed e MaddAddam) com apenas uma publicação traduzida. Continuando nos gêneros literários ficcionais, a autora também produziu oito (8) coletâneas de contos, oito (8) histórias infantis e uma (1) história em quadrinhos. Dessa produção, os contos foram mais traduzidos (5 coletâneas traduzidas) e um dos livros infantis. Contudo, Atwood também tem vasta produção em outros gêneros, como poesia, quase desconhecida para o público brasileiro (de 16 publicações, apenas uma traduzida), e como gêneros de não ficção, a saber, ensaios de crítica e teoria, que tomam a escrita de literatura como centralidade, que somam 10 publicações, das quais apenas 3 foram traduzidas para o público brasileiro.

Neste trabalho, adotamos como recorte de análise as narrativas distópicas da autora, que ganharam atenção do público a partir de adaptações televisivas. Dos 16 romances de Atwood, 6 são consideradas narrativas distópicas e, destas 6 narrativas, 5 foram traduzidas e publicadas no Brasil pela editora Rocco, e apresentam reedições e novas publicações em consonância com a maior popularização da escritora a partir dos anos 2010. Ao contrário das obras das demais escritoras de narrativas distópicas publicadas pela editora Rocco e outras editoras brasileiras, as de Atwood não são lançadas pelo selo jovem da editora, mas pelo selo principal. Essas considerações são apoiadas pelos achados da pesquisa construídos com suporte do programa AntConc: observamos nos paratextos (capas, contracapas e orelhas) que a escritora e suas obras são associadas inicialmente ao gênero de ficção científica e posteriormente à ficção especulativa ou distopia, e há o destaque à notoriedade da escritora, aos prêmios recebidos, ao alcance das obras pela crítica e tradução, evidenciando o cânone doméstico da autora para o público brasileiro, que se concentra nos seus

Distopia e(m) paratradução: reescrevendo Margaret Atwood para o público brasileiro 
romances, particularmente os especulativos, deixando em segundo plano suas outras produções ficcionais e não ficcionais.

Esses dados sobre circulação nos ajudam a construir uma historiografia da leitura de literatura traduzida e a compreender qual é o cânone doméstico construído no Brasil para a escritora Margaret Atwood. Os achados iniciais sustentam o que pesquisas exploratórias anteriores apontam: grande parte da tradução de escritoras contempla suas produções de ficção, particularmente romances, e em geral elas são traduzidas tardiamente, quando já estão consolidadas como escritoras, com reconhecimento de seus pares, premiações, e consistente produção paratextual sobre suas obras, por meio de textos críticos e traduções.

O estudo da tradução como reescrita, que considera e destaca não só o texto literário mas também outros produtos que compõem o sistema literário (resenhas, resumos, críticas, adaptações, etc.), dialoga com o estudo dos paratextos e, logo, ao conceito de paratradução, abordado nesse trabalho. A focalização dos paratextos em tradução nos possibilita, com uso de análise de corpora, analisar como os paratextos cumprem sua função de porta de entrada da tradução, seduzindo e construindo expectativas do leitor a partir da apresentação da escritora, do texto e do gênero para o público; os motivos que levaram à escolha dos textos traduzidos; a posição da literatura traduzida (centro ou periferia) no sistema literário brasileiro; o processo de circulação das traduções literárias e historiografia da literatura traduzida; o processo de construção de cânones domésticos de determinados autores ou gêneros.

Desse modo, essas investigações permitem a compreensão do amplo fenômeno tradutório como processo de reescrita do texto literário para determinado sistema cultural, como o estudo de caso dos textos distópicos de Margaret Atwood, que desvelam o processo de reescrita dessa escritora e do subgênero distopia/ficção especulativa para leitores brasileiros, a partir dos paratextos, iluminando aspectos do projeto literário da escritora e do papel do mercado editorial e seus atores na circulação de textos literários traduzidos. 
Referências

ATWOOD, Margaret. MaddAddão. Tradução de Márcia Frazão. Rio de Janeiro: Rocco, 2019.

ATWOOD, Margaret. O ano do dilúvio. Tradução de Márcia Frazão. 2. Ed. Rio de Janeiro: Rocco, 2018.

ATWOOD, Margaret. O conto da aia. Tradução de Ana Deiró. 2. Ed. Rio de Janeiro: Rocco, 2017.

ATWOOD, Margaret. Oryx e Crake. Tradução de Léa Viveiros de Castro. Rio de Janeiro: Rocco, 2004.

ATWOOD, Margaret. Oryx e Crake. Tradução de Léa Viveiros de Castro. 2. Ed. Rio de Janeiro: Rocco, 2018.

ATWOOD, Margaret. Os testamentos. Tradução de Simone Campos. Rio de Janeiro: Rocco, 2019.

ATWOOD, Margaret. Writing Utopia. In: ATWOOD, Margaret. Writing with intent: Essays, Reviews, Personal prose: 1983-2005. New York: Carroll and Graf Publishers, 2005, p. 92-100.

BATCHELOR, Kathryn. Paratexts. In: BAKER, Mona; SALDANHA, Gabriela (ed.). Routledge Encyclopedia of Translation Studies. 3. Ed. London; New York. NY: 2020. p. 401-405.

CÂMARA. Elisa Oliveira. O paratexto na tarefa do tradutor. 2014. Dissertação (Mestrado em Linguística Aplicada) - Universidade Estadual de Campinas. São Paulo. 2014.

EVEN-ZOHAR, Itamar. 1990. Polysystem Studies, Poetics Today, vol. 1, n. 1, p. 1-51.

KUŹNICKI, Sławomir. Margaret Atwood's Dystopian Fiction: Fire Is Being Eaten. Cambridge Scholars Publishing. 2017.

LEFEVERE, A. Tradução, reescrita e manipulação da fama literária. Tradução de Claudia Matos Seligmann. Bauru: Edusc, 2007.

Distopia e(m) paratradução: reescrevendo Margaret Atwood para o público brasileiro 
MOYLAN, TOM. Scraps of the Untainted Sky: Science Fiction, Utopia, Dystopia. Boulder: Westview Press, 2000.

NETO, Pedro Fortunato de Oliveira. Representações utópicas e distópicas na trilogia Maddaddam, de Margaret Atwood. 2018. Dissertação (Mestrado em Linguística e Literatura) - Universidade Federal de Alagoas. 2018.

PEREIRA, Eliatan da Silva; SALVADORI, Juliana Cristina. A reescrita da ambiguidade narrativa: estudo de caso da tradução de Vulgo Grace de Margaret Atwood. In: VASCONCELOS, Adaylson Wagner Souza de (org.). Letras e Linguística: Estrutura e Funcionamento. Ponta Grossa, PR: Atena, 2020. Cap. 6, p. 61-77.

SARGENT, Lyman Tower. What Is a Utopia? Morus: Utopia e Renascimento. Campinas: Unicamp, 2005, n. 2, p. 153-160.

SOUZA, Renata Pires de. Armageddon has only begun: the ustopian imagination in Margaret Atwood's Oryx and Crake. 2014. Dissertação (Mestrado em Letras) - Universidade Federal do Rio Grande do Sul. 2014.

THOMAS, P. L. (ed.) Science Fiction and Speculative Fiction: Challenging Genres. Boston: Sense Publishers. 2013.

VENUTI. Lawrence. Escândalos da Tradução. São Paulo: Editora Unesp, 2019. 